\title{
Comparison of Single Versus Multifraction Radiotherapy in Palliation of Painful Bone Metastases
}

\author{
Anthialisha Nongkynrih", Anil Kumar Dhulla, b, Vivek Kaushal ${ }^{\mathrm{a}}$, Rajeev Atri ${ }^{\mathrm{a}}$, \\ Rakesh Dhankhar $^{\mathrm{a}}$, Karun Kamboja
}

\begin{abstract}
Background: Bone is a common site of dissemination in advanced cancer accounting for one-third of all distant metastases. Various fractionation schedules of radiotherapy have been used for palliation of bone metastases. The aim of this study was to compare three schedules of external radiation therapy ( 8 Gy single session versus $20 \mathrm{~Gy} / 5$ fractions versus $30 \mathrm{~Gy} / 10$ fractions) for palliative management of bone metastases.
\end{abstract}

Methods: In the present study, 60 patients of bone metastases from any primary site were enrolled and randomly divided into three groups of 20 patients each by draw of lots. These patients received palliative external beam radiation therapy to the involved site. Patients were given 8 Gy single session, $20 \mathrm{~Gy} / 5$ fractions/1 week and $30 \mathrm{~Gy} / 10$ fractions/2 weeks in groups I, II and III, respectively.

Results: The percentage of patients with overall pain relief was $80 \%$ in group I, $75 \%$ in group II and $85 \%$ in group III $(\mathrm{P}=0.7)$. The number of patients with complete pain relief was 4 (20\%) in each group. Maximum patients got pain relief at 4 weeks post-radiotherapy. The number of patients with improved performance status was 4 (20\%) in group II and $2(10 \%)$ each in groups I and III $(\mathrm{P}=0.5)$. Thirteen $(65 \%)$ patients in each of the groups had decreased analgesic requirement at 2-month follow-up. Retreatment rate was more in the single fraction (20\%) compared to only $5 \%$ in group II and none in the group III $(\mathrm{P}=0.05)$.

Conclusion: From the present study we conclude that 8 Gy single fraction is as effective as multifraction radiotherapy for the palliation of painful bone metastases. However, for a center like ours being the only Government Tertiary Cancer Care Centre in the State, general consensus drawn after this study, recommends external radiation therapy $20 \mathrm{~Gy} / 5$ fraction regimen to be an appropriate means of palliation of painful bone metastases.

Keywords: Bone metastases; Palliative radiation therapy; Fractiona-

Manuscript submitted May 8, 2018, accepted June 11, 2018

aDepartment of Radiation Oncology, Regional Cancer Centre, Pt. BD Sharma Post Graduate Institute of Medical Sciences, Rohtak, Haryana, India

${ }^{b}$ Corresponding Author: Anil Kumar Dhull, Department of Radiation Oncology, Post Graduate Institute of Medical Sciences, PO Box 100, GPO Rohtak124001,Haryana, India. Email: anilkdhull@gmail.com

doi: https://doi.org/10.14740/wjon1118w tion; Pain palliation

\section{Introduction}

Metastatic bone disease is a common problem encountered in oncology practice [1]. Of all cancer patients, about $50 \%$ develop metastases in their lifetime [2]. In advanced cancer, bones are the third most common site of metastases [3] and the common primary sites responsible are lung, breast and prostate. Other primary malignancies causing bone metastases are urinary bladder, kidney, uterus, melanoma and thyroid [4]. Skeletal metastases are usually multiple, solitary metastases and are seen only in $10 \%$ cases [5]. Bone metastasis cause pain directly through local invasion and indirectly through alteration of the remodelling activity of osteoblasts and osteoclasts [6]. Proper care of bone metastases requires inter-disciplinary multispecialty coordination [7]. The management of bone metastases includes radiotherapy, chemotherapy, hormone therapy, surgery, radionuclide and supportive therapy alone or in combination [8]. The treatment intent is usually palliative and treatment goal includes pain relief, preservation of function, mobility and quality of life [5]. Radiotherapy is the most effective treatment for bone metastases [9] and $60-80 \%$ of patients respond to external beam radiation therapy (EBRT) with 25$30 \%$ of patients attaining complete pain relief [7].

To compare three schedules of external radiation therapy ( 8 Gy single session versus $20 \mathrm{~Gy} / 5$ fractions versus 30 Gy/10 fractions) for palliative management of bone metastases and evaluate the intensity of pain/pain palliation using visual analog scale (VAS), analgesic requirement and performance status using Karnofsky performance scale (KPS) and Eastern Cooperative Oncology Group (ECOG) scale in these patients before and after treatment.

\section{Materials and Methods}

In the present study, 60 patients of bone metastases from any primary site were enrolled and randomly divided into three groups of 20 patients each by draw of lots. The current study was first approved by our Institutional Review Board (IRB). All the enrolled patients received palliative external beam radiation therapy to the involved site. Patients were given 8 Gy 
Table 1. Patient Characteristics

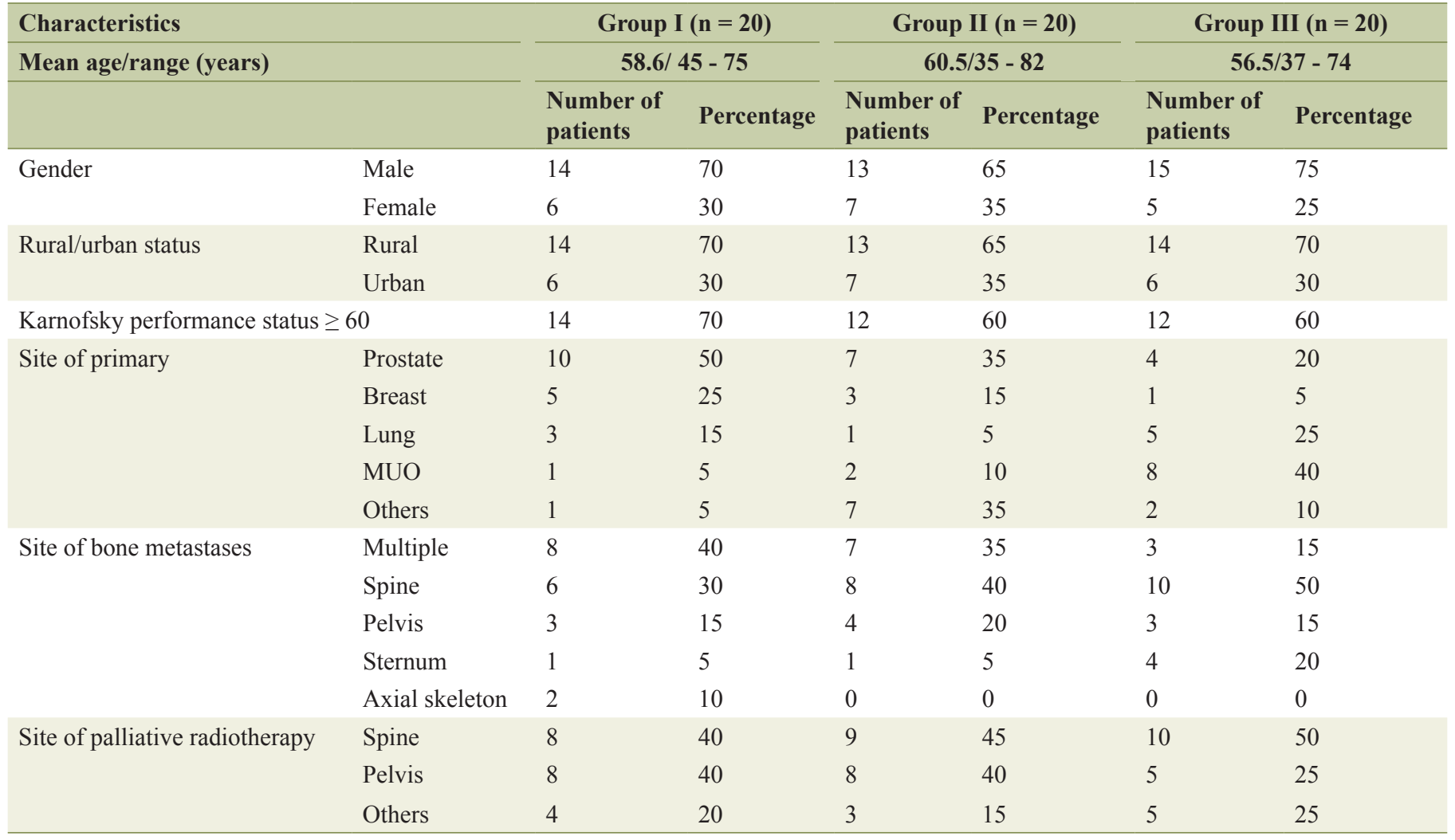

single session, $20 \mathrm{~Gy} / 5$ fractions/1 week and $30 \mathrm{~Gy} / 10$ fractions/2 weeks in groups I, II and III, respectively.

Patients who had previous radiotherapy to the region concerned, or any co-morbid conditions to which the patient's symptoms could be attributed or were pregnant were excluded from the study. In all the groups, external beam radiation was delivered on a telecobalt machine taking appropriate margins as per guidelines.

Patients were followed up for a total duration of 6 months, that is, weekly for 1 month, after completion of radiotherapy and then monthly up to 6 months. At each follow-up, patients were assessed for pain palliation using the VAS, analgesic requirement and functional outcome using the ECOG performance scale and the KPS.

Overall pain response is defined as decrease in pain score by at least two points with respect to the pre-treatment value. Complete pain response is defined as achieving a pain score of 0 at any point during follow-up. Duration of overall pain response is defined as time from initial response till return of pain to its baseline value.

\section{Results}

The baseline characteristics of the patients in all the groups were comparable and are described in Table 1. The mean ages of the patients were 58.6, 60.5 and 56.5 years in groups I, II and III, respectively. Seventy percent of patients were males and $68 \%$ were from rural background. Pre-treatment KPS $\geq 60$ was seen in $70 \%$ of group I and $60 \%$ patients each of groups II and III. Prostate was the most common primary site comprising $35 \%$ of all cases followed by lung and breast $(22 \%$ and $15 \%$, respectively). In group I, most patients presented with multiple sites of bony metastases (40\%). In groups II and III, spine was the most common site of metastases ( $40 \%$ and $50 \%$, respectively). In each group, spine was the most common site of radiotherapy $(40 \%$, $45 \%$ and $50 \%$ in groups I, II and III, respectively) followed by pelvis (40\%, 40\% and $25 \%$ in groups I, II and III, respectively).

The post-treatment observations of the patients in the three groups are described in Table 2 . The percentage of patients with overall pain relief was $80 \%$ in group I, $75 \%$ in group II and $85 \%$ in group III $(\mathrm{P}=0.7)$. The number of patients with complete pain relief was $4(20 \%)$ in each group. Maximum patients got pain relief at 4 weeks post-radiotherapy. The mean pain score before treatment was 80,82 , and 88 in groups I, II and III, respectively $(\mathrm{P}=0.02)$. The minimum mean pain score was observed in the third month $(31.5,37.8$ and 31.6 in groups I, II and III, respectively). At the fifth and sixth month follow-up, there was an increase in mean pain score from na$\operatorname{dir}(44.5,50.5$ and 45.5 in groups I, II and III, respectively) but never equal to or above pre-treatment values. The number of patients with improved performance status was $4(20 \%)$ in group II and $2(10 \%)$ each in groups I and III $(\mathrm{P}=0.5)$. Thirteen $(65 \%)$ patients in each of the groups had decreased analgesic requirement at 2-month follow-up. However, there was a trend to increase in use of analgesics after 3-month follow-up 
Table 2. Post-Treatment Observations

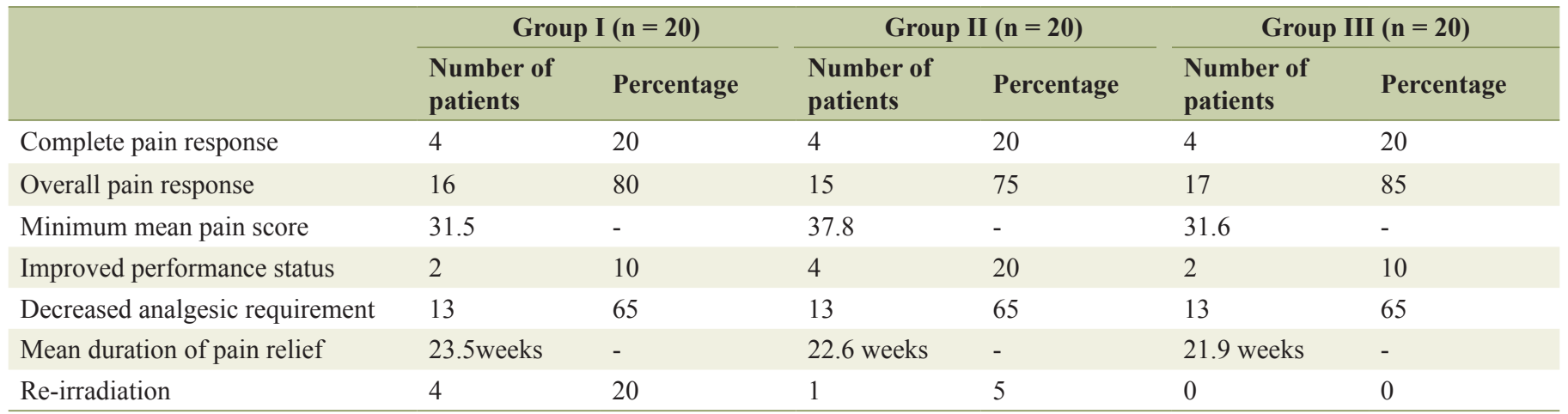

due to recurrence of pain. At the second month follow-up, $25 \%$ patients in each group were free of analgesic use. There was a downward shift in WHO pain ladder from use of narcotics to simple analgesics/NSAIDS in all the groups. At the fourth week of follow-up, use of narcotics reduced from $45 \%$ to $30 \%$, while use of simple analgesics increased from $30 \%$ to $45 \%$ in group I. Similarly, in group II use of narcotics reduced from $60 \%$ to $25 \%$ accompanied by an increase in use of simple analgesics from $40 \%$ to $50 \%$. The use of narcotics also decreased in group III from $50 \%$ to $10 \%$ supplemented by an increase in use of simple analgesics from $20 \%$ to $50 \%$. The mean durations of pain relief among responders was 23.5 weeks, 22.6 weeks and 21.9 weeks in the groups I, II and III, respectively $(\mathrm{P}=0.817)$. Four $(20 \%)$ patients of group I underwent re-irradiation compared to only one patient in group II and none in the third group $(\mathrm{P}=0.05)$.

The economic impact of the multifraction regimens in relation to cost of travel from home to treatment center and back was assessed and is summarized in Table 3. The expenditure is more economical in group I as compared to other groups as group II being 5-day treatment schedule while group III being 10-day treatment schedule.

\section{Discussion}

The treatment modality of choice for palliation of metastatic bone metastases is considered to be local site radiotherapy [10]. There are various fractionation schedules of radiotherapy used for the palliation of bone metastases. Various studies conducted worldwide have shown single session radiotherapy to be equally effective as multifraction radiotherapy in palliation of bone metastases [11-13]. A recent meta-analysis to find the role of radiotherapy in bone metastases have shown no statistically difference in complete response or overall response to radiotherapy among various fractionations but found higher retreatment rates in the single fraction arms [10].

The Bone Trial Working Party Study Group (BTWPG) reported a large-scale trial, which compared 8 Gy in a single fraction versus 20 Gy in 5 fractions or 30 Gy in 10 fractions in 765 patients. There were no significant differences in the time to first improvement in pain, time to complete pain relief, or time to the first increase in pain at any time up to 12 months from randomization. Furthermore, the class of analgesic used and the adverse events also showed no significant differences. According to the authors, a single fraction of 8 Gy was as safe and effective as a multifraction regimen for the palliation of metastatic bone pain for at least 12 months. However, retreatment was twice as common after 8 Gy than after multifraction radiotherapy [14]. In literature, various other randomized studies were conducted to establish the results of different fractionation schedules of palliative radiotherapy in bone metastases to compare their results (Table 4). It was concluded that single fraction radiotherapy was as effective as multifraction regimens in palliation of bone metastases but retreatment was more frequent in the single fraction regimen [15-20]. A recent update of the ASTRO (American Society of Therapeutic Radiology and Oncology) evidence-based guideline regarding palliative radiotherapy for painful bone metastases concluded that there was strong evidence of pain relief equivalency between single and multiple fraction regimens for bone metastases [21]. Similar results were observed in our present study wherein

Table 3. Assessment of Economic Impact in the Multifraction Regimens

\begin{tabular}{|c|c|c|c|}
\hline & Group I & Group II & Group III \\
\hline $\begin{array}{l}\text { Average distance travelled per day for radiation treatment } \\
\text { (i.e. from home to treatment center and back) }\end{array}$ & $101 \mathrm{~km}$ & $102.4 \mathrm{~km}$ & $97 \mathrm{~km}$ \\
\hline $\begin{array}{l}\text { Average distance travelled from home to treatment } \\
\text { center for complete radiation treatment }\end{array}$ & $101 \mathrm{~km}$ & $512 \mathrm{~km}$ & $970 \mathrm{~km}$ \\
\hline $\begin{array}{l}\text { Total expenditure on travel during radiation treatment } \\
\text { considering average cost of travel at Rs } 10 / \mathrm{km}\end{array}$ & $\begin{array}{l}\text { Rs } 1,010 \\
\text { per patient }\end{array}$ & $\begin{array}{l}\text { Rs } 5,120 \\
\text { per patient }\end{array}$ & $\begin{array}{l}\text { Rs } 9,700 \\
\text { per patient }\end{array}$ \\
\hline
\end{tabular}


Table 4. Randomized Trials Comparing Single versus Multifraction Radiotherapy in Bone Metastases

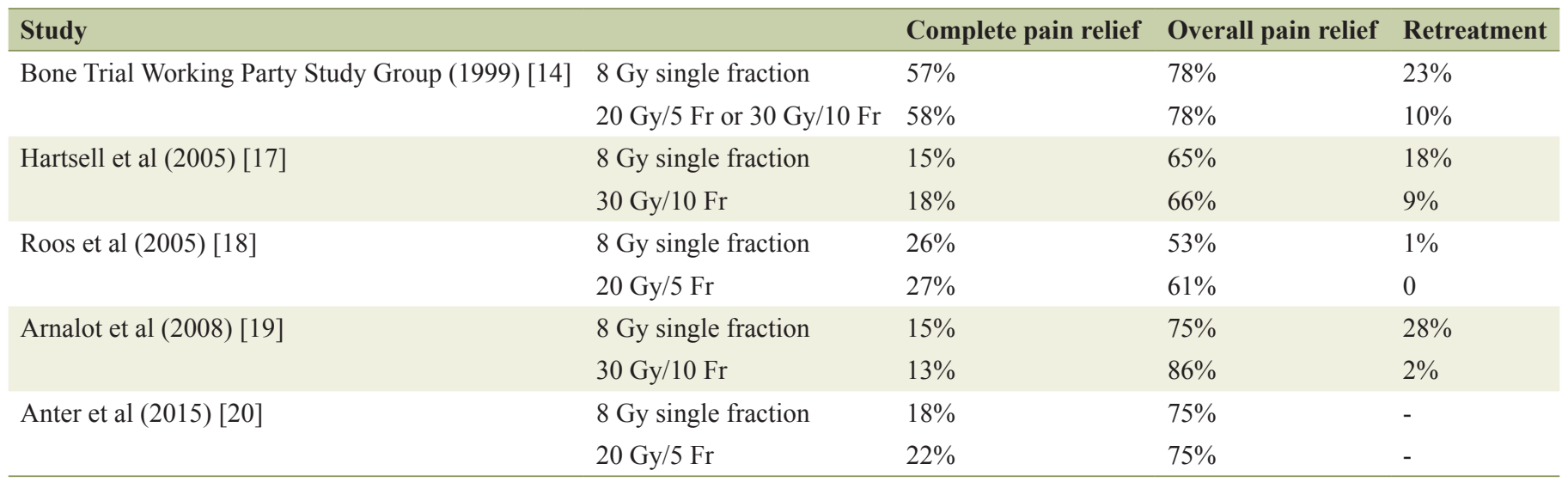

there was no statistical difference in complete pain relief $(20 \%$ in each group) and overall pain relief (80\%, 75\% and $85 \%$ in groups I, II and III, respectively $(\mathrm{P}=0.7)$. However, retreatment rate was more in the single fraction $(20 \%)$ compared to only one patient in group II and none in the group III $(\mathrm{P}=$ 0.05). Also, when comparing between the multifractional regimens, group I appears to be most economical (Rs 1,010 per patient); however, because of added advantage of most effective palliation in group II, it appears to be economically more feasible and favorable, because total expenditure on travel during radiation treatment is almost double in group III (Rs 9,700 per patient) as compared to group II (Rs 5,120 per patient).

\section{Conclusions}

From the present study we conclude that 8 Gy single fraction is as effective as multifraction radiotherapy for the palliation of painful bone metastases. However, for a center like ours being the only Government Tertiary Cancer Care Centre in the State, general consensus drawn from this study, recommends external radiation therapy $20 \mathrm{~Gy} / 5$ fraction regimen to be an appropriate means of palliation of painful bone metastases as it has the same level of palliation as the $30 \mathrm{~Gy} / 10$ fraction arm with shorter total duration of treatment. The socioeconomic cost of a single fraction arm is superior to other arms; however, because of effective palliation in group II, and almost half of the economic burden as compared to group III, 5-fraction arm shows added advantage in form of socioeconomic feasibility and effective palliation over the other arms.

\section{Acknowledgments}

We are thankful for our Departmental team for their help in collection of data and statistical analysis.

\section{Conflicts of Interest}

There is no conflict of interest.

\section{References}

1. Agarawal JP, Swangsilpa T, van der Linden Y, Rades D, Jeremic B, Hoskin PJ. The role of external beam radiotherapy in the management of bone metastases. Clin Oncol (R Coll Radiol). 2006;18(10):747-760.

2. Arcangeli G, Micheli A, Arcangeli G, Giannarelli D, La Pasta O, Tollis A, Vitullo A, et al. The responsiveness of bone metastases to radiotherapy: the effect of site, histology and radiation dose on pain relief. Radiother Oncol. 1989;14(2):95-101.

3. Sharma K, Bahadur AK, Mohanta PK, Singh K, Rathi AK. Palliative treatment of painful bone metastases: Does fractionation matter. Indian J Palliative Care. 2008;14:715.

4. Hartsell WF, Santosh Y. Palliation of bone metastases. In: Halperin EC, Perez CA, Brady LW, editors. Principles and practice of radiation oncology. Volume 1.5 th ed. Philadelphia: Lippincott Williams and Wilkin; 2013. p. 1778-1791.

5. Falkmer U, Jarhult J, Wersall P, Cavallin-Stahl E. A systematic overview of radiation therapy effects in skeletal metastases. Acta Oncol. 2003;42(5-6):620-633.

6. Johnstone C, Lutz ST. External beam radiotherapy and bone metastases. Ann Palliat Med. 2014;3(2):114-122.

7. Lutz S, Berk L, Chang E, Chow E, Hahn C, Hoskin P, Howell D, et al. Palliative radiotherapy for bone metastases: an ASTRO evidence-based guideline. Int J Radiat Oncol Biol Phys. 2011;79(4):965-976.

8. Singh K. Management of Bone metastases. Radiat Oncol. 2003;3:88-92.

9. Needham PR, Mithal NP, Hoskin PJ. Radiotherapy for bone pain. J R Soc Med. 1994;87(9):503-505.

10. Kougioumtzopoulou A, Zygogianni A, Liakouli Z, Kypraiou E, Kouloulias V. The role of radiotherapy in bone metastases: A critical review of current literature. Eur J Cancer Care (Engl). 2017;26(6):e12724.

11. Chow E, Danjoux C, Wong R, Szumacher E, Franssen E, Fung K, Finkelstein J, et al. Palliation of bone metastases: a survey of patterns of practice among Canadian radiation oncologists. Radiother Oncol. 2000;56(3):305-314. 
12. Ben-Josef E, Shamsa F, Williams AO, Porter AT. Radiotherapeutic management of osseous metastases: a survey of current patterns of care. Int J Radiat Oncol Biol Phys. 1998;40(4):915-921.

13. Roos DE. Continuing reluctance to use single fractions of radiotherapy for metastatic bone pain: an Australian and New Zealand practice survey and literature review. Radiother Oncol. 2000;56(3):315-322.

14. The Bone Trial Working Party. 8 Gy single fraction radiotherapy for the treatment of metastatic skeletal pain: randomised comparison with a multifraction schedule over 12 months of patient follow-up. Bone Pain Trial Working Party. Radiother Oncol. 1999;52(2):111-121.

15. Jilla S, Ratnam SV, Naidu KVJR, Monica I, Ranadheer M, Suresh P. Study of three different fractionation regimens in palliative radiotherapy for painful bone metastases. J Clin Sci Res. 2014;3:90-96.

16. Kaasa S, Brenne E, Lund JA, Fayers P, Falkmer U, Holmberg $M$, Lagerlund $M$, et al. Prospective randomised multicenter trial on single fraction radiotherapy (8 Gy x 1) versus multiple fractions (3 Gy x 10) in the treatment of painful bone metastases. Radiother Oncol. 2006;79(3):278-284.

17. Hartsell WF, Scott CB, Bruner DW, Scarantino CW,
Ivker RA, Roach M, 3rd, Suh JH, et al. Randomized trial of short- versus long-course radiotherapy for palliation of painful bone metastases. J Natl Cancer Inst. 2005;97(11):798-804.

18. Roos DE, Turner SL, O'Brien PC, Smith JG, Spry NA, Burmeister BH, Hoskin PJ, et al. Randomized trial of 8 Gy in 1 versus 20 Gy in 5 fractions of radiotherapy for neuropathic pain due to bone metastases (Trans-Tasman Radiation Oncology Group, TROG 96.05). Radiother Oncol. 2005;75(1):54-63.

19. Foro Arnalot P, Fontanals AV, Galceran JC, Lynd F, Latiesas XS, de Dios NR, Castillejo AR, et al. Randomized clinical trial with two palliative radiotherapy regimens in painful bone metastases: 30 Gy in 10 fractions compared with 8 Gy in single fraction. Radiother Oncol. 2008;89(2):150-155.

20. Anter A. Single Fraction versus Multiple Fraction Radiotherapy for treatment of painful bone metastases: a Prospective Study; Mansoura experience. Forum Clin Oncol. 2015;6:8-13.

21. Lutz S, Balboni T, Jones J, Lo S, Petit J, Rich SE, Wong $\mathrm{R}$, et al. Palliative radiation therapy for bone metastases: Update of an ASTRO Evidence-Based Guideline. Pract Radiat Oncol. 2017;7(1):4-12. 